\title{
Letters
}

Website: www.bmj.com

Email: letters@bmj.com

\section{Guidelines for cervical screening await scientific evaluation}

EDITOR-In a news item about cervical screening in England ${ }^{1}$ Wise refers to a report by the National Audit Office. ${ }^{2}$ The office is particularly critical of serious failings in the interpretation of cervical smears in a small number of laboratories. The laboratory at the Hospital of St Cross in Rugby is included among these laboratories. In fact, a massive rescreening exercise at the hospital did not find any serious errors of interpretation, and the original reports were considered to be substantially correct and within the accepted operating limits of the smear test.

The National Audit Office and the public assume that any deviation from the national guidelines for reporting rates represents mistakes by the laboratory. It is therefore interesting that, although the results at the hospital in Rugby were outside these guidelines, no serious errors were identified. This raises the question of whether the guidelines are an appropriate measure of laboratory performance.

The guidelines themselves have come under considerable criticism in the pathology literature because of the lack of scientific evidence on which they are based. ${ }^{3}$ One of their own authors has been particularly outspoken on the subject. ${ }^{4}$ Though some of these arguments may seem of academic

\section{Advice to authors}

We prefer to receive all responses electronically, sent either directly to our website or to the editorial office as email or on a disk. Processing your letter will be delayed unless it arrives in an electronic form.

We are now posting all direct submissions to our website within 72 hours of receipt and our intention is to post all other electronic submissions there as well. All responses will be eligible for publication in the paper journal.

Responses should be under 400 words and relate to articles published in the preceding month. They should include $\leqslant 5$ references, in the Vancouver style, including one to the BMJ article to which they relate. We welcome illustrations.

Please supply each author's current appointment and full address, and a phone or fax number or email address for the corresponding author. We ask authors to declare any competing interest.

Letters will be edited and may be shortened.

www.bmj.com

letters@bmj.com interest, cytology departments are being forced to close or merge as a result of the guidelines, which await scientific evaluation. Many staff feel threatened by the prescriptive way in which the guidelines have been introduced and applied and by the lack of understanding by the lay public and media of the limitations of the smear test.

The incidence of and mortality from cervical cancer in the United Kingdom have shown accelerated falls since the introduction of organised screening (J Patnick, NHS cervical screening programme information sheet, 21 Nov 1996). Of course there is room for improvement, but it is ironic that the publication of various reports designed to improve the service could lead to its eventual collapse through staff leaving the profession.

J F Nottingham Consultant histopathologist George Eliot NHS Trust, Nuneaton, Warwickshire CV10 7DJ

1 Wise J. Improvements needed in cervical screening in England. BMJ 1998;316:1261. (25 April)

2 National Audit Office. The performance of the NHS cervical screening programme in England. London: Stationery Office, 998.

3 Harvey JA. Guidelines, standards, and evidence in cervica screening; a personal view. Cytopathology 1998;9:2-5.

4 Slater DN. Quality assurance in cervical cytopathologytime for a more evidence based approach. Cytopatholog 1997;8:75-8.

\section{Secondary prevention in acute myocardial infarction}

\section{Data cited from two studies were inaccurate}

EdiTor-Mehta and Eagle's review of secondary prevention in acute myocardial infarction contains some important errors. ${ }^{1}$ Firstly, in table 3 the relative risks of death cited for references 17, 18, and 20 are in fact percentage reductions in mortality divided by 100 . These figures are so out of keeping with the rest of the table that it is surprising they were not spotted earlier. Even as percentage mortality reductions they are inaccurate. In the original paper by Pfeffer et al (ref 17) the 21\% reduction observed referred to cardiovascular rather than total mortality, and the $95 \%$ confidence interval was $5 \%$ to $35 \%$ rather than to $25 \%$. Pfeffer et al calculated a $19 \%$ reduction in total mortality $(95 \%$ confidence interval $3 \%$ to $32 \%, \mathrm{P}=0.019),{ }^{2}$ although a crude calculation gives $17 \%$.

Secondly, the data cited from the paper by Ambrosioni et al (ref 20) refer to a combined end point (death or severe congestive heart failure) rather than to total mortality. The mortality statistics are 51/784 $(6.5 \%)$ in the placebo group and $38 / 772$ $(4.9 \%)$ in the treatment group, so that the risk reduction is $25 \%(-11 \%$ to $60 \%$; $\mathrm{P}=0.19)^{3}$ and the relative risk 0.75 .

These are the only two original articles that I have checked. The errors are of fact rather than typography and raise questions about the remainder of the article.

Niall A Herity Senior registrar in cardiology

Antrim Hospital, Antrim BT41 2RI

nherity@dial.pipex.com

1 Mehta RH, Eagle KA. Secondary prevention in acute myocardial infarction. BMJ 1998;316:838-42. (14 March)

2 Pfeffer MA, Braunwald E, Moye LA, Basta L, Brown EJ Cuddy TE, et al. Effect of captopril on mortality and morbidity in patients with left ventricular dysfunction after myocardial infarction. Results of the survival and ventricular enlargement trial. N Engl J Med 1992;327:669-77.

3 Ambrosioni E, Borghi C, Magnani B for the SMILE study investigators. The effect of the angiotensin-converting enzyme inhibitor zofenopril on mortality and morbidity after anterior myocardial infarction. $N$ Engl J Med 1995; $332: 80-5$

\section{Authors' reply}

Editor-As Herity points out, the relative risks of death cited in table 3 are the percentage reduction in mortality divided by 100. In a footnote to the table we stated that these were "cited as percentages in original paper." A more appropriate footnote might have been "cited as percentage reduction in mortality." This might have helped avoid the confusion created by our effort to simplify the tables. The same is true for table 4: the risk of death cited is the percentage reduction in mortality.

We acknowledge that our paper contains two errors, as Herity points out. Firstly, the reduction in total mortality in the survival and ventricular enlargement trial (Pfeffer et al, ref 17) was 19\% (95\% confidence interval $3 \%$ to $32 \%$; $=0.019$ ). The reduction in mortality cited in our article is the reduction in cardiovascular mortality. Secondly, the reduction in mortality in the survival of myocardial infarction long-term evaluation trial (Ambrosioni et al, ref 20) was $25 \%(6.5 \%$ in the placebo group versus $4.9 \%$ in the treatment group; $-11 \%$ to $60 \% ; \mathrm{P}=0.19)$. The figures cited in our article are the combined end points of death or congestive heart failure. Our article should therefore be read with the above corrections.

Rajendra H Mehta Cardiology fellow 1500 E Medical Center Drive, B1F245, University Hospital, Ann Arbor, MI 48109, USA

Kim A Eagle Albion Walter Hewlett professor Department of Internal Medicine, 1500 E Medical Center Drive, TC 3119 N, Ann Arbor 
Diet containing oil-rich fish confers more benefit than some pharmacological regimens

Editor-Mehta and Eagle's review of the evidence on preventing secondary acute myocardial infarction highlights how much less we know about this than about managing acute myocardial infarctions. ${ }^{1}$ Although the authors make brief reference to the benefits of non-pharmacological regimens, they fail to include proved benefits of dietary advice in preventing secondary myocardial infarctions. The randomised controlled diet and reinfarction trial, in 2033 male survivors of previous myocardial infarction, showed a 29\% reduction in two year all cause mortality in patients advised to eat two portions oil-rich fish a week. ${ }^{2}$ This simple and cheap dietary intervention was highly acceptable (compliance rate $78 \%$ over two years), with no known important side effects.

The benefits for survivors of myocardial infarction of eating oil-rich fish far exceed those expected from some pharmacological regimens included in Mehta and Eagle's review. Furthermore, these agents will often be more expensive than dietary advice, have contraindications to their use, and may have clinically important side effects. We suggest that if the benefits in the diet and reinfarction trial, or even smaller benefits, had been obtained from a drug then more support would be given to its use.

Roger Harrison NHS research fellow Wigan and Bolton Health Authority, Wigan WN1 1AH

Michael Burr Senior lecturer public health medicine University of Wales College of Medicine, Centre for Applied Public Health Medicine, Cardiff CF1 3NW

1 Mehta R, Eagle K. Secondary prevention in acute myocardial infarction. BMJ 1998;316:838-42. (14 March.)

2 Burr ML, Gilbert JF, Holliday RM, Elwood PC, Fehily AM,

Rogers S, et al. Effects of changes in fat, fish and fibre

Ror reinfarction trial (DART). Lancet 1989;ii:757-61.

Long term insulin treatment is important in secondary prevention in diabetic patients

EDITOR-Mehta and Eagle's review of secondary prevention in acute myocardial infarction does not mention the extensive work being done in the diabetic population. ${ }^{1}$ Hyperglycaemia is a risk factor for developing coronary artery disease in non-insulin dependent diabetes mellitus. ${ }^{2}$ Malmberg et al have shown that in diabetic patients with a blood glucose concentration of $>11 \mathrm{mmol} / \mathrm{l}$ intensive insulin treatment at the time of the acute myocardial infarction followed by long term insulin treatment caused a relative reduction in mortality of $30 \%{ }^{3}$ Most of this reduction occurred once the patients had been discharged from hospital and continued at three year follow up. Those who benefited the most were low risk patients who had not previously taken insulin. We contend that long term insulin treatment, even in patients whose diabetes has previously been well controlled with diet or tablets, should be an important aspect of secondary prevention in this group.
Early death and reinfarction are almost twice as common in diabetic as in nondiabetic patients after a myocardial infarction. $\beta$ Blockers in diabetic patients have been underused owing to fears of prolonging hypoglycaemia and masking symptoms. These fears have been overstated. In long term studies mortality is reduced by a third in non-diabetic patients treated with $\beta$ blockers but by $48 \%$ in similarly treated diabetic patients. ${ }^{4}$ Diabetic patients should not be denied the advantages of $\beta$ blockade.

The role of aspirin in secondary prevention in diabetic patients is not clear. There may be higher platelet turnover in diabetic patients, necessitating higher doses of aspirin. The second international study of infarct survival did not show any benefit of aspirin at a dose of $165 \mathrm{mg}$ in the diabetic subgroup. $^{5}$ We recommend that $300 \mathrm{mg}$ should be the dose of aspirin in secondary prevention for diabetic patients.

Focusing on the special needs of a high risk group such as diabetic patients after a myocardial infarction will promote more efficient use of resources and result in an improved outcome. These patients should not be disadvantaged further by being denied optimal medical treatment.

Angus Nightingale Specialist registrar in cardiology Andrew Marshall Clinical director

South West Cardiothoracic Centre, Department of Cardiology, Derriford Hospital, Plymouth PL6 8DH

1 Mehta RH, Eagle KA. Secondary prevention in acute myocardial infarction. $B M J$ 1998;316:838-42. (14 March.)

2 Turner RC, Millns H, Neil HAW, Stratton IM, Manley SE Matthews DR, et al. Risk factors for coronary artery disease in non-insulin dependent diabetes mellitus: United in non-insulin dependent diabetes mellitus: United 1998;

3 Malmberg K. Prospective randomised study of intensive insulin treatment on long term survival after acute myocardial infarction in patients with diabetes mellitus. BMJ 1997;314:1512-5

4 Kjekshus J, Gilpin E, Cali G, Blackley AR, Henning H, Ros J. Diabetic patients and beta-blockers after acute myocardial infarction. Eur Heart J 1990;11:43-50.

5 Yudkin JS. Which diabetic patients should be taking aspirin? BMJ 1995;311:641-2

\section{Verapamil is alternative to $\beta$ blockers in} patients without congestive heart failure

EDITOR-In their review of secondary prevention in acute myocardial infarction Mehta and Eagle state: "Verapamil does not reduce mortality or reinfarction." This statement is not evidence based and seems to express a personal view of the authors. Verapamil has recently been approved for secondary prevention in several European countries, including France and England. The European Society of Cardiology's task force on the management of acute myocardial infarction states that verapamil and diltiazem "may be appropriate when $\beta$ blockers are contraindicated."

The basis for using verapamil is the Danish verapamil infarction trial II.. ${ }^{3}$ The important findings in this trial were a 20\% lower rate of major events (first reinfarction or death) in patients treated with verapami than in patients treated with placebo $(18.6 \%$ v $21.6 \%, \mathrm{P}=0.03$; hazard ratio $0.80(95 \%$ confidence interval 0.64 to 0.99 )) and a significantly lower mortality in patients without congestive heart failure treated with verapamil than in those treated with placebo $(7.7 \%$ v $11.8 \%, \mathrm{P}=0.02$; hazard ratio 0.64 (0.44 to 0.94$))$; there was no difference in mortality between the two treatment groups in patients with congestive heart failure. The conclusions from the trial were that verapamil prevented major events, that the effect was restricted to patients without congestive heart failure, and that no harmful effect was seen in patients with congestive heart failure.

Three secondary prevention studies in which verapamil was used have been published: the Danish verapamil infarction trial II, the calcium antagonist reinfarction Italian study, ${ }^{4}$ and a study of verapamil and trandolapril versus trandolapril alone. ${ }^{5}$ A meta-analysis of these three studies that carried out showed a significantly lower rate of reinfarction in patients treated with verapamil than in those treated with placebo (odds ratio 0.77 ( 0.63 to 0.95 ); $\mathrm{P}=0.04$ ). If all six early and late intervention studies are combined in a meta-analysis a $24 \%$ reduction in reinfarctions is shown with verapamil (odds ratio 0.76 (0.62 to 0.93 ); $\mathrm{P}=0.02$ ).

$\beta$ Blockers have been shown to improve prognosis after a myocardial infarction. The question is whether we have anything to offer for secondary prevention in patients with contraindications or intolerance to $\beta$ blockers. Verapamil (and diltiazem) are alternatives in these patients if they do not have congestive heart failure.

Jørgen Fischer Hansen Head of department of cardiology

Cardiovascular Medicine Y, Bispebjerg Hospital, DK-2400 Copenhagen NV, Denmark

1 Mehta RH, Eagle KA. Secondary prevention in acute myocardial infarction. BMJ 1998;316:838-42. (14 March.)

2 Task Force on the Management of Acute Myocardial Infarction of the European Society of Cardiology. Acute myocardial infarction: pre-hospital and in-hospital management. Eur Heart J 1996;16:43-63.

3 Danish Study Group on Verapamil in Myocardial Infarction. The effect of verapamil on mortality and major events after myocardial infarction. The Danish verapamil infarction trial (DAVIT) II. Am J Cardiol 1990;66:779-85.

4 Rengo F, Carbonin P, Pahor M, De Caprio L, Bernabei R,

Ferrar $\mathrm{N}$, et a and the CRIS Investigators. Bernabei R, Ferrara $\mathrm{N}$, et al and the CRIS Investigators. A controlled tral of verapamil in patients after acute myocardial infarcstudy (CRIS) . Am J Comdiol 1996; $77: 365-9$.

5 Hansen JF, Hagerup L, Sigurd B, Pedersen F, Mellemgaard Hansen JF, Hagerup L, Sigurd B, Pedersen F, Mellemgaar $\mathrm{K}$, Pedersen-Bjergaard $\mathrm{O}$, et al, for the DAVIT Study Group. Cardiac event rates after acute myocardial infarction in patients treated wh verapamil and trandolapril versus trandolapril alone. Am J Cardiol 1997;79:738-41.

\section{Clinicians must promote value of diet} containing oil-rich fish

EDitor-The clinical review by Mehta and Eagle illustrates all too clearly the preoccupation of modern medicine with costly high tech drug treatment. ${ }^{1}$ Though the authors pay lip service to diet by suggesting that survivors of heart attack should be advised to eat a low fat diet, their major failure must surely be in omitting any reference to fish. With so many credible, peer reviewed studies now showing the value of the long chain omega-3 polyunsaturates, it must surely rank as one of the first recommendations after infarction.

Albert et al recently reported a $50 \%$ reduction in risk of death in fish eaters compared with people who did not eat fish 
weekly. ${ }^{2}$ The Japanese, who eat more fish per capita than any other population in developed countries, have the lowest death rate from heart disease as well as an admirable longevity. Dolecek and Grandits, studying the data from the multiple risk factor intervention trial, found an inverse doseresponse relation between intake of omega-3 polyunsaturates and risk of death from heart attack as well as all cause mortality.

Clinically, survivors of heart attack who follow advice to eat oil-rich fish two or three times a week reduce their subsequent risk of death by $30 \%{ }^{4}$ Singh et al reported $50 \%$ fewer deaths among survivors of heart attack who took $1800 \mathrm{mg}$ of fish oil daily in a double blind, placebo controlled trial.

We know that eating more oil-rich fish such as herring, mackerel, and salmon (or taking supplements of fish oil) lowers serum triglyceride concentrations, blood pressure, and viscosity and reduces the risk of thrombosis and arrhythmia. If fish oil were a patentable drug huge sums would have been spent on promoting its use on the basis of these clinical benefits, and thousands of premature heart deaths could have been avoided. As it is not commercially exploitable in this way, clinicians must promote its value, relative simplicity, freedom from harmful side effects, and low cost.

R D Rice Chief executive

Fish Foundation, PO Box 24, Tiverton, Devon EX16 4QQ

The Fish Foundation is a non-profit organisation that seeks to inform health professionals and the lay public about the benefits of consuming more of the long chain omega-3 fatty acids from fish.

Mehta RH, Eagle KA. Secondary prevention in acute myocardial infarction. BMJ 1998;316:838-42. (14 March.)

2 Albert CM, Hennekens CH, Odonnell CJ, Ajani UA, Cary VJ, Willett WC, et al. Fish consumption and risk of sudden cardiac death JAMA 1998:279:23-8.

3 Dolecek TA, Grandits G. Dietary polyunsaturated fatty acids and mortality in the multiple risk factor intervention trial (MRFIT). In: Simopoulos A Kifer RR, Martin RE Bartrial (MRR . . low SM, Health effects of $\omega 3$ polyunsaturated fatty acids in

4 Burr ML, Fehily AM, Gilbert JF, Rogers S, Holliday RM, Elwood P, et al. Effects of changes in fat, fish, and fibre intakes on death and myocardial reinfarction: diet and reinfarction trial (DART). Lancet 1989;ii:757-61.

5 Singh RB, Niaz MA, Sharma JP, Kumar R, Rastogi V, Moshiri M. Randomized double blind trial of fish oil and mustard oil in patients with suspected acute myocardia infarction. Cardiovasc Drugs Ther 1997;11:485-91.

\section{Acute excited states and sudden death}

EDITOR-In his letter Pounder ${ }^{1}$ relies on physiological research by Reay et $\mathrm{al}^{2}$ that has recently been shown to be methodologically incorrect. ${ }^{3}$ Chan et al showed that even the most extreme (hogtied) restraint positions combined with exercise do not produce hypoxia or any other clinically relevant change in oxygenation or ventilation, provided that correct methods of measurement are used. ${ }^{3}$ We do not of course recommend hogtying as a form of restraint.

We thank Karch and Stephens for drawing attention in their letter to the interesting neurochemical associations between cocaine use, hyperthermia, and sudden death. We agree that prudent postmortem management should include neck dissection to rule out neck compression as well as measurements of brain drug concentrations, but as psychiatrists we are more interested in the living than the dead and how to prevent the living becoming the dead.

H G Kennedy Consultant forensic psychiatrist

F R Farnham Lecturer in forensic psychiatry

North London Forensic Service, Enfield

Community Care NHS Trust, Chase Farm Hospital, Enfield, Middlesex EN2 8JL

1 Pounder D. Acute excited states and sudden death. $B M J$ 1998;316:1171. (11 April)

2 Reay DT, Howard JD, Fligner CL, Ward RJ. The effects of positional restraint on oxygen saturation and heart rate following exercise. Am J Forens Med Pathol 1988;9:16-8.

3 Chan TC, Vilke GM, Neuman T, Clausen JL. Restrain position and positional asphyxia Ann Emerg Med 1997;30: tion an

4 Karch SB, Stephens BG. Acute excited states and sudden death. $B M J$ 1998:316:1171.(11 April)

(a) 5 Farnham FR, Kennedy HG. Acute excited states and sudden death. BMJ 1997;315:1107-8.

\section{Health needs assessment is not required for priority setting}

EDITOR-The series of articles on health needs assessment provided insights into how the approach could be used to describe health problems in populations and to identify inequalities in health and access to services. ${ }^{1-3}$ The authors of the articles failed to recognise, however, that prioritising healthcare services on the basis of need can lead to inefficient use of resources.

Allocating finite healthcare resources according to the total amount of ill health in the population-whether this is measured by lives lost, morbidity, or any other agreed measure of need-overlooks the potential for patients to benefit from healthcare interventions and ignores the costs of those interventions. How, for example, would an epidemiologically driven approach prioritise healthcare services if conditions with great need (however defined) were not amenable to treatment and conditions with less need were amenable to an array of low cost, effective treatments? Needs assessment cannot form the basis of an efficient strategy for planning and purchasing health services.

The economic approach offers a more satisfactory framework for prioritising healthcare services. It estimates the incremental costs and benefits of altering the existing balance of expenditure between healthcare programmes, independent of any changes in the overall health budget. ${ }^{4}$ It does have limitations, not least the paucity of adequate data on the costs and benefits of healthcare interventions with which to make strategic decisions and disagreements about the merits of alternative measures of health benefit (for example, the quality adjusted life year and the healthy year equivalent). These limitations, however, should not distract from the appeal of an approach that aims to maximise health gains within available resources.

The proponents of needs assessment might argue that an understanding of the distribution of severity of health problems within the population is required, even where maximising quality adjusted life years or healthy year equivalents is the agreed objective. With this understanding the incremental cost per unit of health gain can be estimated at each level of unmet need. Even this view, however, cannot be accepted uncritically. For most services, unmet need is so great that gain in quality adjusted life years or healthy year equivalents can be assumed to remain constant over the range of any marginal increase in the provision of services. Moreover, the economic approach takes existing expenditure patterns as the starting point and uses evidence from formal and informal sources to examine the effects of small changes to those patterns.

Stavros Petrou Health economist

National Perinatal Epidemiology Unit, Radcliffe Infirmary, Oxford OX2 6HE

1 Wright J, Williams R, Wilkinson JR. Development and importance of health needs assessment. BMJ 1998; 316:1310-3. (25 April.)

2 Williams R, Wright J. Epidemiological issues in health needs assessment. BMJ 1998;316:1379-82. (2 May.)

3 Stevens A, Gillam S. Needs assessment: from theory to practice. BMJ 1998;316:1448-52. (9 May.)

4 Cohen D. Marginal analysis in practice: an alternative to needs assessment for contracting health care. $B M J 1994$; 309:781-5.

\section{Insider view of rationing down under}

EDITOR-Bridgewater gave an outsider's view of the assessment and treatment of patients requiring coronary artery bypass grafting in New Zealand, ${ }^{1}$ particularly since the introduction of a priority scoring system. ${ }^{2}$ Several points need clarification.

Firstly, his example of a 50 year old man with class II angina and triple vessel disease who scores 34 points is typical of many who would receive bypass surgery in other developed countries. ${ }^{3}$ Bridgewater commented that acceptance for surgery at our hospital in these circumstances was "strongly resisted" by clinicians attending our weekly combined conference with the cardiac surgeons. This is true, but it arises because the New Zealand government will not fund operations on patients in public hospitals who score $<35$ points.

The government established a threshold of 35 points to ration services. It also had the laudable aim of introducing a booking system for all patients who met the threshold, with such patients being booked a date for operation within six months of being listed. Unfortunately, the funding to implement this scheme has not come and the initiative has faltered. At our hospital most patients who undergo coronary artery bypass surgery have unstable symptoms and critical disease. ${ }^{4}$ Resources are not sufficient to treat those who might receive a similar degree of benefit from bypass surgery but who are at a lower immediate risk of adverse cardiac events.

Secondly, Bridgewater noted that patients who did not meet the threshold of 35 points were placed on a review list, but he 
was unaware of the outcome for this group. When the government's threshold of 35 points for bypass surgery was introduced in May 1996, 130 of the 264 patients then on the waiting list at our hospital were removed because they did not reach the entry threshold. In the 18 months that followed 59 patients received surgery within the public system because of worsening symptoms and regrading, nine had operations done privately, and one was treated by angioplasty. Three patients died without receiving coronary surgery.

Finally, the weekly combined conference with our surgical colleagues concentrates on difficult and controversial cases. Neither inhospital emergencies (about two thirds of the workload) nor straightforward cases are usually discussed. Emergency cases are operated on urgently after appropriate consultation and straightforward cases are booked for bypass surgery by the referring cardiologist. For these reasons the conference may give a misleading impression to a visiting surgeon. We believe that the overall pattern of referrals is somewhat less adversely weighted than Bridgewater has appreciated.

Trevor M Agnew Cardiologist

Mark W I Webster Cardiologist

Cardiology Department, Green Lane Hospital,

Auckland, New Zealand

1 Bridgewater B. Is rationing down under upside down? $B M$ J 1998;316:1251. (18 April.)

2 Hadorn DC, Holmes AC. The New Zealand priority criteria project. Part 2: Coronary artery bypass surgery. $B M$ 1997;314:135

3 Carroll RJ, Horn SD, Soderfeldt B, James BC, Malmberg L International comparison of waiting times for selected cardiovascular procedures. I Am Coll Cardiol 1995:25: $557-63$.

4 Agnew TM, Whitlock RML, Neutze JM, Kerr AR. Waiting lists for coronary artery surgery: can they be better organised? NZ Med J 1994;107:21 1-5.

\section{How should different life expectancies be valued?}

\section{Existential model may be better than} scale that uses quality adjusted life years

EDITOR-Problems with the valuation of life expectancy and quality adjusted life years ${ }^{1}$ can be traced to the underlying philosophical paradigm. The quality adjusted life year paradigm is based on 19th century classical utilitarianism. The greatest good is perfect health, which is valued at 1; being dead (and the event of death) has the value of 0 . Other states are given values of $<1$; states judged worse than death may be given negative values. $^{2}$

This century, philosophers such as Martin Heidegger and Sir Karl Popper have put forward ideas that differ from those of the utilitarians and suggest an alternative model of how to value health. Heidegger's premise is that we are unaware of things when they are normal; our conscious concern is with the abnormal. For example, we are not aware of using a door handle when we enter a room unless it is broken. ${ }^{3}$ We are not consciously aware that our body is healthy; we become aware of our body only when we are
Valuations when scale based on quality adjusted life years (QALYS) and existential model based on Heidegger's and Popper's premises is used

\begin{tabular}{lcc} 
& $\begin{array}{c}\text { Scale based } \\
\text { on QALYs }\end{array}$ & $\begin{array}{c}\text { Existential } \\
\text { model }\end{array}$ \\
\hline Healthy for one year & 1 & 0 \\
\hline Illness for one year & $<1$ & $>0$ \\
\hline Event of death & 0 & $>0$ \\
\hline Dead for one year & 0 & 0
\end{tabular}

ill, injured, or dying. This existential approach directs attention to aspects of health that we are aware of, such as distress, disability, and impending death.

Popper exhorts us to minimise misery and misfortune, not seek to maximise good. These are not symmetrical. One person's suffering cannot be traded for another person's happiness. There is an analogy here with Popper's premise that the task of science is to eliminate false theories, not to attain ultimate truth. ${ }^{4}$

Deaths at different ages and in different circumstances have different consequences and should be valued differently. Once one is dead one has ceased to exist (at least for direct health care). This distinction, between the event of death and the state of being dead, is ignored in the literature about quality adjusted life years.

The table compares the valuations when the QALY scale and an existential model are used. It shows fundamental asymmetry. The task of commissioners of health care is to allocate resources in order to minimise the overall consequences of morbidity and death for their population. An existential model provides a direct indicator of these consequences. Unfortunately, the scale that uses quality adjusted life years creates a utilitarian distortion.

Tim Benson Chairman

Electronic Point of Care, Wembley, Middlesex HA0 1SU

tb@abies.co.uk

1 Waugh N, Scott D. How should different life expectancies be valued? BMJ 1998;316:1316. (25 April.)

2 Rosser R. From health indicators to quality adjusted life years: technical and ethical issues. In: Hopkins A, Costain $\mathrm{D}$, eds. Measuring the outcomes of medical care. London: Royal College of Physicians of London, 1990:1-17.

3 Dreyfus H. Husserl, Heidegger and modern existentialism. In: Magee B. The great philosophers: an introduction to Western philosophy. London: BBC Books, 1987:252-77.

4 Popper K. The open society and its enemies. Vol L. The spell of Plato. 5th ed. London: Routledge Kegan Paul, 1966:284-5.

\section{Diminishing marginal utility and} discounting future effects have similar consequences

EDITOR-Waugh and Scott propose that health effects should be tripled or doubled when total life expectancy is below 6 months or 12 months, respectively, when the duration of lifetime left is taken into account in economic evaluations. ${ }^{1}$ Economic theory may be of help in the issues that they raise.

Firstly, the principle of attaching more weight to benefits gained when life expectancy is short corresponds to the economic principle of diminishing marginal utility, reflecting the idea that giving an additional sandwich to someone who has little to eat is preferable to giving it to someone with a lot to eat. This principle implies that giving an additional quality adjusted life year to a person with a quality adjusted life expectancy of 20 years is less valuable than giving one to a person with a life expectancy of only 3 months. This notion is already used implicitly: lifesaving lung transplantation, with huge costs per quality adjusted life year, is considered worthwhile, whereas prevention programmes aimed at people with high cholesterol concentrations, with much lower costs per quality adjusted life year, are not considered cost effective. The same notion may explain the acceptance of high costs in the last year(s) of life, when potential health gains and life expectancy are often low. Waugh and Scott's proposal to triple or double health effects is as arbitrary as is making no adjustment, and more research is needed to find the appropriate weights.

Secondly, correcting for diminishing marginal utility may partly solve the fact that people with a short life expectancy may be more willing to accept a poor quality of life than people with a longer life expectancy. This relates to one of the principles underlying quality adjusted life years-that of constant proportional trade off; this means that equivalence between 10 years in health state $\mathrm{A}$ and 5 years in health state B implies equivalence between 10 months in $\mathrm{A}$ and 5 months in B. Again, more research is needed to indicate how the concept of quality adjusted life years should be adapted for situations involving short life expectancies.

Finally, Waugh and Scott mention discounting future effects. Discounting and diminishing marginal utility are two different subjects, with similar consequences, but from completely different backgrounds. Thus they should be treated separately.

Werner Brouwer Research fellow

Ben van Hout Senior research fellow

Institute for Medical Technology Assessment Erasmus University, Rotterdam PO Box 1738, 3000 DR Rotterdam, Netherlands

1 Waugh N, Scott D. How should different life expectancies be valued? BMJ 1998;316:1316. (25 April.)

\section{When can odds ratios mislead?}

\section{Odds ratios should be used only in} case-control studies and logistic regression analyses

EDITOR-Expressing the results of clinical trials and systematic reviews in terms of odds ratios can be more seriously misleading than Davies et al advise us. ${ }^{1}$ They gave a correct analysis of situations in which odds ratios are used to describe increases in event rates, but their consideration of the more common situation, in which treatments reduce event rates, is short sighted. Here, effectiveness is more commonly expressed as the percentage relative risk reduction $(100 \times(1-$ relative risk) $\%$ ) than the actual relative risk. The discrepancy between a relative risk reduction and the equivalent relative odds reduction $(100 \times(1$ - odds ratio $) \%)$ can be misleading. 
When event rates are high (commonly the case in trials and systematic reviews) the relative odds reduction can be many times larger than the equivalent relative risk reduction.

For example, Brent et al report results of a trial of a programme aimed at increasing the duration of breast feeding. ${ }^{2}$ By three months 32/51(63\%) women had stopped breast feeding in the intervention group, compared with 52/57(91\%) in the control group. Whereas the relative risk reduction is $31 \%$ the relative odds reduction is $84 \%$ : nearly three times as large. The same problem can occur in systematic reviews: a summary of the results of seven trials of antimicrobial treatment on premature rupture of membranes showed a $49 \%$ relative odds reduction of delivery by seven days, whereas the relative risk reduction was only $19 \% .^{3}$

Although relative odds and relative risk reductions always go in the same direction, these discrepancies in magnitude are large enough to mislead. Good estimates of treatment effects are essential for clinicians to be able to balance the relative probabilities of the good and bad outcomes that could be caused by a treatment.

The only safe use of odds ratios is in case-control studies and logistic regression analyses, where they are the best estimates of relative risks that can be obtained. Theoretical mathematical arguments for using odds ratios in other circumstances have not been supported by empirical studies.

In clinical trials and systematic reviews of trials there is no reason for compromising interpretation by reporting results in terms of odds rather than risks. ${ }^{45}$ Authors and journal editors should ensure that the results of trials and systematic reviews are reported as relative risks unless there is a convincing argument otherwise.

Jon Deeks Medical statistician

Centre for Statistics in Medicine, Institute of Health Sciences, Oxford OX3 7LF

J.Deeks@icrf.icnet.uk

1 Davies HTO, Crombie IK, Tavakoli M. When can odds ratios mislead? BMJ 1998:316:989-91. (28 March.)

2 Brent NB, Redd B, Dworetz A, D'Amico F, Greenberg J. Breast-feeding in a low-income population. Arch Pediatr

3 Mercer BM, Arheart KL. Antimicrobial therapy in expectMercer BM, Arheart KL. Antimicrobial therapy in expect-
ant management of preterm premature rupture of ant management of preterm pre
membranes. Lancet 1995;346:1271-9.

membranes. Lancet 1995;346:1271-9.
4 Sackett DL, Deeks JJ, Altman DG. Down with odds ratios! Evidence-Based Med 1996;1:164-6.

5 Sinclair JC, Bracken MB. Clinically useful measures of effect in binary analyses of randomized trials. J Clin Epidemiol 1994;47:881-90.

Avoidable systematic error in estimating treatment effects must not be tolerated

EDITOR-Davies et al conclude that "qualitative judgments based on interpreting odds ratios as though they were relative risks are unlikely to be seriously in error." ${ }^{\text {Statisti- }}$ cians may be satisfied with qualitative judgments, but doctors and patients must make quantitative judgments.

Relative risk and its complement, relative risk reduction, are widely used and well understood measures of treatment effect. Only case-control studies do not permit direct calculation of relative risk. Why then,

Number needed to treat calculated from misinterpretation of odds ratio $(\mathrm{OR})$ as if it were relative risk (RR) and from true RR

\begin{tabular}{|c|c|c|c|c|}
\hline \multirow[b]{3}{*}{$\mathbf{O R}$} & \multicolumn{4}{|c|}{ Number needed to treat } \\
\hline & \multicolumn{2}{|c|}{ Control event rate $\mathbf{5 0} \%$} & \multicolumn{2}{|c|}{ Control event rate $\mathbf{8 0} \%$} \\
\hline & When $\mathbf{O R}$ used as $\mathbf{R R}$ & When true RR used & When $\mathbf{O R}$ used as $\mathbf{R R}$ & When true RR used \\
\hline 0.5 & 4.0 & 6.0 & 2.5 & 7.5 \\
\hline$\overline{0.6}$ & 5.0 & 8.0 & 3.1 & 10.6 \\
\hline 0.7 & 6.7 & 11.4 & 4.2 & 15.6 \\
\hline 0.8 & 10.0 & 18.0 & 6.3 & 26.2 \\
\hline 0.9 & 20.0 & 40.0 & 12.5 & 57.5 \\
\hline
\end{tabular}

when measures of treatment effect come from research that uses stronger designs, would clinicians accept odds ratios as being roughly equivalent to relative risks rather than demand to know the relative risk itself? If our goal is to provide as valid an estimate of a treatment effect as possible, why introduce any unnecessary systematic error?

Davies et al suggest that there is no important concern in interpreting an odds ratio of 0.66 (reduction in death after management in specialist stroke units) as if it were the relative risk (the true relative risk was 0.81 in their example). We disagree. How treatment effects are described influences doctors' perceptions of efficacy. ${ }^{2}{ }^{3}$ Moreover, the number needed to treat, a statistic widely used to express the clinical importance of treatment effects, ${ }^{4}$ is seriously underestimated (by 45\%) when the odds ratio is interpreted as the relative risk (in their example, it would be calculated erroneously as 5.3 rather than the true 9.7).

Knowing the number of patients one needs to treat to prevent one patient having the adverse target event is particularly useful in deciding whether to treat. Clinicians will treat patients when the number needed to treat is lower than a threshold number at which benefits of treatment wholly offset adverse events attributable to it. ${ }^{5}$ Interpreting an odds ratio as if it were a relative risk introduces a systematic error in the estimation of the number needed to treat and hence in decisions on treatment: treatment will be recommended when it should not be.

The table shows the number needed to treat calculated erroneously from misinterpretation of the odds ratio as if it were the relative risk and correctly from the true relative risk. The calculations are done at high control event rates and over a range of odds ratios. When the control event rate is high, interpretation of the odds ratio as the relative risk results in a systematic and important underestimate of the number needed to treat.

When relative risk can be directly calculated, it should be. There is no reason to tolerate avoidable systematic error in estimating treatment effects.

Michael B Bracken Professor

Yale University School of Medicine, Department of Epidemiology and Public Health, New Haven, CT, 06510, USA

John C Sinclair Professor of paediatrics

McMaster University, Hamilton, Ontario, Canada L8N 3 Z5

1 Davies HTO, Crombie IK, Tavakoli M. When can odds ratios mislead? BMJ 1998;316:989-91. (28 March.)
2 Forrow L, Taylor WC, Arnold RM. Absolutely relative: how research results are summarized can affect treatment decisions. Am J Med 1992;92:121-4.

3 Naylor CD, Chen E, Strauss B. Measured enthusiasm: does the method of reporting trial results alter perceptions of therapeutic effectiveness? Ann Intern Med 1992;117:916-

4 Sinclair JC, Bracken MB. Clinically useful measures of effect in binary analyses of randomized trials. J Clin Epidemiol 1994:47:881-9.

5 Guyatt GH, Sackett DL, Sinclair JC, Haywood R, Cook DJ,

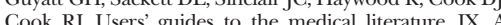
Cook RJ. Users guides to the medical literature. IX. A method for grading health care recommendations. JAMA

\section{Authors' reply}

EDITOR-Both letters make interesting points about odds ratios but do not actually uncover any shortcomings in our paper. We did not advocate the use of odds ratios. Instead our paper addressed the issue of how common events must be, and how big effect sizes must be, before the odds ratio becomes a misleading estimate of the relative risk. Our main aim was to put to rest the widespread misconception that the odds ratio is a good approximation to the relative risk only when rare events are being dealt with. Our conclusion was that "serious divergence between the odds ratio and the relative risk only occurs with large effects on groups at high initial risk."

In our paper we clarified this. So long as the event rate in both the intervention and the control groups is less than $30 \%$ and the effect size is no more than moderate (say, a halving or a doubling of risk) then interpreting an odds ratio as a relative risk will overestimate the size of the effect by less than one fifth. This is a far cry from the requirement that events be rare. The authors of the letters confirm that problems can arise with higher event rates-all their examples use unusually high rates of between $50 \%$ and $91 \%$

In the paper we were quite clear that we were concerned with broad qualitative judgments of treatment effects and not precise quantitative estimates of the size of any effect. Though it is true, as Bracken and Sinclair state, that "doctors and patients must make quantitative judgments" we should be wary of invoking too great a precision in making these judgments. Many factors may influence the observed effect size of a treatment-for example, the nature of the group of patients studied, variations in the healthcare setting and concomitant care, and, of course, the play of chance.

On one thing we are in clear agreement: odds ratios can lead to confusion and alternative measures should be used when these are available. Authors reporting on 
prospective studies should be encouraged to report the actual relative risk or relative risk reduction. Better still, as Bracken and Sinclair point out, numbers needed to treat (which measure absolute benefit) are more useful when treatment decisions are made than either relative risks or odds ratios (which measure only relative benefit). Nevertheless, when odds ratios are encountered, guidance on their interpretation is of more use than outright rejection.

Huw Talfryn Oakley Davies Lecturer in healthcare management

Manouche Tavakoli Lecturer in health and industrial economics

Department of Management, University of St Andrews, St Andrews, Fife KY19 9AL

Iain Kinloch Crombie Reader in epidemiology Department of Epidemiology and Public Health, University of Dundee, Ninewells Hospital and Medical School, Dundee DD1 9SY

\section{Long term pharmacotherapy of depression}

\section{Tricyclic antidepressants should not be first line treatment}

EDITOR-In his editorial Edwards correctly points out the high rate of recurrence of disease among patients with major depression and the importance of long term treatment. ${ }^{1}$ We dispute his advice to use tricyclic antidepressants as first line treatment.

He states that the dropout rate in clinical trials is $1-5 \%$ less in patients given selective serotonin reuptake inhibitors than in patients given tricyclic antidepressants. A metaanalysis of 62 randomised controlled trials found that the total discontinuation rate was $10 \%$ lower with selective serotonin reuptake inhibitors and the dropout rate due to side effects 25\% lower. ${ }^{2}$ These dropout rates imply that patients are being inadequately treated with tricyclic antidepressants and may require further psychiatric treatment and possibly admission to hospital.

Edwards admits that death is more likely to result from overdoses of older tricyclic antidepressants than from overdoses of newer compounds. He quotes a single questionnaire study to back up his claim that this difference may be due to doctors prescribing older antidepressants to patients who are more prone to suicide. The Health of the Nation sets a target for reducing the rate of suicide by $15 \%$ by 2000 and suggests that this may be achieved by reducing the availability of means to do so. ${ }^{3}$ The famous reduction in suicide rates that followed the introduction of natural gas as well as more recent research supports this policy. ${ }^{4}$

Edwards calculates the average net ingredient cost of an NHS prescription for a selective serotonin reuptake inhibitor in 1995 to be 227.21 . Our calculations based on figures obtained from a 1995 edition of the British National Formulary show it to be £23.43. He uses his figures to extrapolate the increase in cost that would be seen if selective serotonin reuptake inhibitors were used as first line treatment for all patients currently prescribed tricyclic antidepressants. The cost of drugs is only around $11 \%$ of the total cost of treating depression. ${ }^{5}$ A review of research on cost effectiveness concluded that newer antidepressants were more cost effective than older drugs when all the costs of depression were taken into account. ${ }^{5}$

Edwards recommends that newer antidepressants should be used to treat patient who are more prone to suicide or accidents. Although risk factors for suicide exist predicting who will do it is impossible. Accident proneness is a vague term that is impossible to assess and use as a means of deciding which drug patients will receive.

Damian Gamble Senior house officer in psychiatry Jogin Thakore Senior lecturer

Academic Department of Psychiatry, Royal London Hospital, London E1 1BB

1 Edwards JG. Long term pharmacotherapy of depression BMJ 1998;316:1180-1. (18 April.)

2 Anderson IM, Tomenson BM. Treatment discontinuation with selective serotonin reuptake inhibitors compared with tricyclic antidepressants: a meta-analysis. BMJ 1995 ; with ticyclic a

3 Department of Health. The health of the nation. London: HMSO, 199

4 Marzuk PM, Leon AC, Tardiff K, Morgan EB, Stajic M, Mann JJ. The effect of access to lethal methods of injury on suicide rates. Arch Gen Psychiatry 1992;49:451-8.

5 Croft R, Gilis P. Economic comparisons of the pharmacotherapy of depression: an overview. Acta Psychiatr Scand 1998;9:241-52.

\section{Impact of side effects of treatment is important in older patients}

EDITOR-The editorial by Edwards on the long term pharmacotherapy of depression warrants further comment. The trials from the American National Institute of Mental Health showed that antidepressants given at full therapeutic doses and continued as maintenance treatment were significantly more beneficial than placebo after five years. ${ }^{2}$ The benefit for maintenance treatment with antidepressants can thus be seen for five years after an index episode of depression and, indeed, for as long as follow up trials have been continued.

In comparing older tricyclic with newer antidepressants, a substantial advantage of preparations such as selective serotonin reuptake inhibitors is that for many of these products the starting dose is likely to be an effective therapeutic dose. This is not the case with tricyclic antidepressants. Many studies in primary care have shown that general practitioners continue to prescribe subtherapeutic doses of tricyclic antidepressants $^{3}$ and that patients receiving subtherapeutic doses consult their doctors more often. Donoghue et al showed an increase in antidepressant prescribing at therapeutic doses in primary care that seemed to be associated with an increase in prescribing of selective serotonin reuptake inhibitors. ${ }^{4}$

The comparatively small advantage associated with selective serotonin reuptake inhibitors compared with tricyclic antidepressants in dropout rates from metaanalyses cannot be assumed to be a valid reflection of daily clinical practice. Patients participating in clinical trials may be more likely to comply with their treatment. Many tricyclic antidepressants are prescribed as twice or thrice daily doses. In practice better compliance with taking the newer antidepressant drugs, many of which can be given once a day, might reasonably be expected.

The impact of side effects from antidepressant treatment on older patients is important. Anticholinergic, antiadrenergic, and antihistaminergic side effects associated with amitriptyline may lead to falls and fractures, which may lead to substantially greater illness than the predominantly gastrointestinal side effects associated with newer preparations.

The time may be ripe for large scale surveys of patient preferences and quality of life measures associated with the side effects of antidepressants to add a further dimension to the debate.

Robert Tobiansky Consultant in old age psychiatry Colindale Hospital, London NW9 5HG

1 Edwards JG. Long term pharmacotherapy of depression. BMJ 1998;316:1180-1. (18 April.)

2 Kupfer DJ, Frank E, Perel JM, Comes C, Mallinger AG, Kupfer DJ, Frank E, Perel JM, Comes C, Mallinger AG,
Thase ME, et al. Five year outcome for maintenance therapies in recurrent depression. Arch Gen Psychiatry 1992;

3 Ali IM. Long term treatment with antidepressants in primary care. Psychiatr Bull 1998;22:15-9.

4 Donoghue J, Tylee A, Wildgust H. Cross-sectional database analysis of antidepressant prescribing in general practice in the United Kingdom, 1993-5. BMJ 1996;313:861-2.

\section{Patients can help doctors decide on treatment}

EDITOR-Edwards has written an editorial full of "shoulds," which had it been written about asthma would have concluded that beclomethasone and salbutamol should be prescribed for those who cannot tolerate isoprenaline and Do-Do tablets. Patients with major depression are not just found in outpatients departments. In the past five years alone, I have treated over 900 such patients in my suburban practice - cases that were diagnosed by history, examination, and using the questionnaires that hospital specialists such as Edwards have developed. Of course, general practitioners see "milder, heterogeneous cases," but they are in addition to, not a substitute for, the real thing.

Neither is it difficult to know why patients stop their treatment. I have been asking them for years and been using that information often to unlearn so much of what I was taught by specialists and academics. In diabetes, asthma, and depression the patient can become the specialist and help the doctor decide whether any form of treatment is still required and how much. Furthermore, if newer antidepressants should be prescribed for "patients who cannot tolerate older antidepressants [and I am talking therapeutic doses here] and/or who have a high risk of suicide by overdose ... [and to those] who are prone to accidents or have cardiovascular disease," I would be prescribing them for nearly all the patients I see anyway, even assuming I knew how to continually identify those at risk or welcomed the extra workload that would be required.

As one result of continued prescribing of tricyclic antidepressants, suicides will continue to occur ("only about $4 \%$," so I guess we shouldn't be too bothered), as will 
subtherapeutic dosing for suboptimal periods of time in people with coexisting diseases who have to be able to drive, operate machinery, or work the hours expected. Right now, thousands of patients with depression in Britain are suffering needlessly while the medical profession sorts out its mind on these issues. In the end, Edwards and others like him distill the complexity down to the net ingredient cost of the drugs. I believe that people and the lives they want to live are worth more-even 4 million psychiatric outpatient attendances. These, like disease episodes in asthma, would reduce anyway if the disease was being better managed by therapeutic doses of less toxic drugs with simpler regimens.

Chris Manning Chairman, Primary Care in Mental Health Group

St John's Health Centre, Twickenham TW1 3PH

Conflict of interest: I have had depression for 12 years.

1 Edwards JG. Long term pharmacotherapy of depression. BMJ 1998;316:1180-1. (18 April.)

\section{Author's reply}

EDITOR-Gamble and Thakore refer to the relative dropout rate from trials, whereas I cited the $1-5 \%$ difference in absolute discontinuation rates. This is much lower than expected from the claims made about the advantages of selective serotonin reuptake inhibitors over older tricyclic antidepressants. The overall dropout rate is important as it is often difficult to be sure whether treatment is stopped because of inefficacy or side effects, or both.

Correlations have been shown between the availability of methods of suicide and fatalities, but decreasing availability may be followed by a compensatory increase in suicides by other methods. ${ }^{2}$ Suicide occurs as often among patients taking new antidepressants as among those taking old antidepressants.

The costs I cited were those incurred by the Department of Health. Because of rationing within the health service and doctors being forced into the distasteful process of prioritising treatment, claims about expensive products need to be critically analysed, methodological uncertainties highlighted, and examples of alternative purchases-for example, community services or coronary bypass operations-given. ${ }^{1}$

It is difficult to generalise from the study cited by Tobiansky (an extension of an earlier three year study ${ }^{3}$ ) as only 20 highly selected patients were included. I based my comments on an overview of larger scale studies lasting two years.

Tobiansky's comments on dosage do not mean that selective serotonin reuptake inhibitors should be prescribed as first line treatment for all patients. Most antidepressants can be prescribed in single daily doses, which lead to better compliance.

The "shoulds" mentioned by Manning relate to widely recommended practices. They are difficult to avoid in an article offering guidance on treatment. I cannot comment on the above average number of patients with major depressive disorders treated by Manning or on his statement on suicidal risk without more knowledge of his diagnostic and prognostic criteria and interview technique.

The percentages of suicides caused by single antidepressants have to be seen in the context of the total debate on the relation between choice of drug and method of suicide. $^{1}$ More important than prescribing safe antidepressants is the assessment of risk. Although accurate long term predictors of suicide do not exist, identifiable subgroups of patients require special short term supervision and care as well as pharmacotherapy.

People do not suffer just because of oversimplistic thinking, indecision, and undue concern over costs but because of limited knowledge of depression and its treatment Cost-benefit analyses help the purchasers of health care to allocate resources in the most productive way. Not to do so would deprive patients of optimum benefits.

I admire Manning's declaration of conflict of interest. Such a declaration militates against the stigma that inhibits people from seeking the treatment they so desperately need.

J Guy Edwards Honorary clinical senior lecturer Department of Psychiatry, Royal South Hants Hospital, Southampton SO9 4PE

1 Edwards JG. Drug choice in depression. Selective serotonin reuptake inhibitors or tricyclic antidepressants? CNS Drugs 1995;4:141-59.

2 Ohberg A, Lonnqvist J, Sarna S, Vuorie E, Penttila A. Trend and availability of suicide methods in Finland. Proposals for restrictive measures. Br J Psychiatry 1995;166:35-43.

3 Frank E, Kupfer DJ, Perel JM, Cornes C, Jarrett DB, Mellinger AG, et al. Three-year outcomes for maintenance therapies in recurrent depression. Arch Gen Psychiatr 1990;47:1093-9.

\section{Admissions for depression have not increased among men in Republic of Ireland}

EDITOR-Shajahan and Cavanagh report a decline in the ratio of the rates of women to men first admitted to Scottish hospitals for depression from 1980 to $1995 .{ }^{1}$ The Health

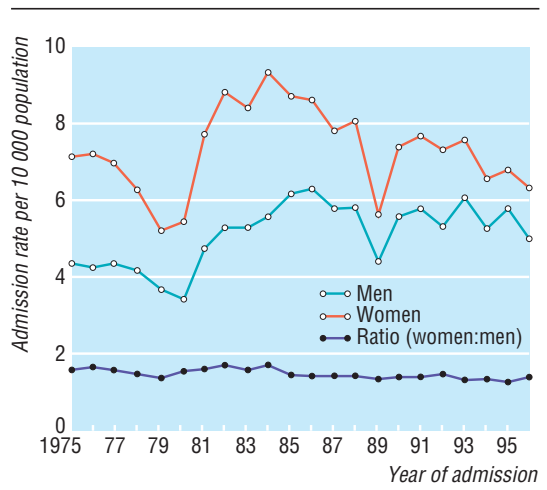

Rates of first admission to hospital for depressive disorders for women and men per 10000 population in Republic of Ireland, 1975-96
Research Board has data from Irish hospitals over 20 years, for which almost identical diagnostic categories were used (ICD-9, 296.1, 296.3, 298.0, 300.4, 309.0, 309.1, and 311). These data give little support to the Scottish experience (figure). Nor do they support an increasing rate of first admissions for men.

D Walsh Consultant psychiatrist

Health Research Board, Dublin 2, Ireland

1 Shajahan P, Cavanagh J. Admission for depression among
men in Scotland, 1980-95: retrospective study. BMJ men in Scotland, 1980-95:

\section{Doctors who do not feel sober enough to drive should avoid helping in medical emergencies}

EDITOR-The ethical debate entitled "Too drunk to care?" raises interesting moral problems but mixes ethical arguments with comments about legal responsibility. ${ }^{1}$ Ethics and the law are different subjects that occasionally overlap; it is dangerous, however, to confuse one with the other. The real question is how much alcohol Cressey had drunk before he found himself in the difficult situation of knowing whether to offer help to a spectator at a sports event who became unconscious after an incident. Once we know the degree of intoxication involved we can comment on the wisdom of his actions and formulate guidelines about the dangers of involvement. Clearly, from a legal perspective the safest course of action is not to get involved at all (however morally questionable that is). There is no duty to rescue in law. Once one becomes embroiled, however, a professional relationship is established and the spectre of negligence looms large.

The answer may come by looking at comparative legal situations. If a person has had an alcoholic drink but believes that a Breathalyser test would show that he or she was sober enough to drive then it is reasonable to say that that person is probably competent to attend a medical emergency. I therefore suggest that if doctors find themselves in Cressey's position and feel compelled to act they should first ask themselves whether they are sober enough to drive. If the answer is yes then proceeding to assist a sick person is probably safe; if the answer is no or there is any uncertainty then it is probably fair to themselves and the patient that they resist, whatever the moral motivation. It is a sad reflection on our litigious society and the effect this has had on the medical profession that all medicine must now be practised defensively and the only truly legally safe course is not to get involved. I fear that society as a whole may now be paving the price for being so ready to sue the medical profession. For some unfortunate people this may be the ultimate price.

J A D Stewart Specialist registrar in general medicine and gastroenterology

Glenfield General Hospital NHS Trust, Leicester LE3 9QP

1 Cressey DM, Rigter H, de Beaufort I, Rees G, Walsh P. Too drunk to care? BMJ 1998;316:1515-7. (16 May.) 